\title{
Influence of tank bottom surface on growth and welfare of Senegalese sole (Solea senegalensis)
}

\author{
C. Almansa, J. Oca, J. Claramunt, L. Reig* \\ Departament d'Enginyeria Agroalimentària i Biotecnologia, Universitat Politècnica de Catalunya BarcelonaTech, C/ Esteve Terrades 8, 08860, Castelldefels, Spain
}

\section{ART ICLE INFO}

\section{Keywords:}

Flatfish

Solea senegalensis

Tank bottom surface

Growth

Welfare

\begin{abstract}
A B S T R A C T
Tank bottom surface is an important question to take into account in flatfish aquaculture considering the intimate contact that the fish have with it. The most usual materials in aquaculture tank surfaces are inert materials such as epoxy resins or plastics with null porosity, and cement that presents a high alkalinity, roughness and porosity. To improve the cement characteristics, silica fume admixture is usually added in construction industry. The aim of this study was to evaluate the effect of three types of tank bottom surfaces on growth and welfare over a Solea senegalensis population. Moreover, the degree of fin erosion, the appearance of skin lesions and malpigmentation patterns were also monitored. The bottom surfaces tested were plain cement (CE), the same plain cement blended with silica fume (10\%) (SF) and epoxy coated surface (EP). Specific growth rate for each bottom surface were compared. The Image Processing Activity Index (IPAI) was used to evaluate the Senegalese sole welfare. Higher SGR and lower IPAI values were obtained in the surface of cement with silica fume, suggesting a higher welfare. The use of plain cement affected negatively the performance of fish, probably due to the high $\mathrm{pH}$ and alkalinity of the water in direct contact with fish skin. The null porosity of EP seems to be related to the main cause of higher activity level of fish kept on it outcoming in lower growth. Silica fume that is frequently use to improve the mechanical characteristics of plain cement, also provides benefits in terms of fish welfare.
\end{abstract}

\section{Introduction}

Senegalese sole (Solea senegalensis), like other flatfishes, is a benthic, carnivorous, marine fish lacking a gas bladder. Its characteristic behavioral traits reflect their bottom-living habit. The skin is asymmetrically pigmented on the eyed side and non-pigmented on the blind side.

Senegalese sole is a flatfish of high commercial value and demand in the wider European market (Morais et al., 2014). It is now being commercially farmed in significant quantities in Europe, mostly in farms located along the Atlantic coast of Portugal, north-west Spain and France (Howell et al., 2011; Rodríguez and Peleteiro, 2014). Sole is mainly produced intensively in land-based facilities using recirculation systems (Howell et al., 2011; Rodríguez and Peleteiro, 2014).

There is a wide variety of materials available for manufacturing suitable tanks for intensive fish culture; they should be inexpensive, durable, non-toxic, easy to manage during production and allow a flexible use. For on-growing sole culture, fiberglass, usually gel-coated on

\footnotetext{
* Corresponding author.

Email address: lourdes.reig@upc.edu (L. Reig)
}

the inner surface, or concrete tanks are used (Imsland et al., 2003; Morais et al., 2014). Fiberglass is lightweight, strong, durable, modestly priced, inert to both fresh and salt water and easy to clean and sterilize. On the other hand large-sized ponds are generally constructed by using concrete. They are strong, durable and easy to construct and manage. Concrete is rather porous and therefore difficult to clean and disinfect. Painting these tanks with a two part epoxy paint will form an impermeable coating reducing both of these drawbacks, but adds considerably to the expense.

The high alkalinity of concrete and $\mathrm{pH}$ (around 13) (Savage et al., 2002) can raise the $\mathrm{pH}$ of the water (Jadhav, 2009) which can result in ammonia accumulation within the fish (Summerfelt et al., 2001) and adversely affect the growth and nutritional state of fish in general (Haywood, 1983; Tomasso, 1994), and S. senegalensis juveniles, in particular (Pinto et al., 2007). The high alkalinity causes cement-related skin injuries that are highly studied in humans (Chung et al., 2007), especially when wet, since dry cement is less dangerous (Superior Health Council, 2015). Generally, any material is considered harmful to skin when its $\mathrm{pH}$ is 11.5 or greater (EU, 2008). The abrasion due to rough 
surfaces as concrete has been related, among other causes, with fin erosion of trout in aquaculture facilities (Kindschi, 1987; Bosakowski and Wagner, 1995; Latremouille, 2003; Hoyle et al., 2007).

To improve concrete properties in the construction industry, silica fume can be added as an admixture. Some mechanical advantages of it are a reduction of concrete porosity, its high early compressive strength and high tensile, flexural strength, and modulus of elasticity; all of these characteristics enhance durability of concrete. Moreover, it presents other chemical advantages that make this admixture a suitable material for aquaculture tank construction. Some of them are its very low permeability to chloride and water intrusion, increased abrasion resistance, and superior resistance to chemical attack from chloride, acids, nitrates and sulfates, etc. It is used, among others, for highway bridges, parking decks, marine structures and deck overlays (Siddique, 2011).

The action of silica fume in concrete has a chemical phase consisting of the pozzolanic reaction, which transforms the weak calcium hydroxide $\left[\mathrm{Ca}(\mathrm{OH})_{2}\right]$ or Portlandite crystals into the strong calcium silicate hydrate gel that produces a $\mathrm{pH}$ reduction of concrete (Toutanji and Bayasi, 1999).

In commercial flatfish culture, when fish are kept on hard bottom tanks without sand, negative consequences have been observed, such as lower growth rates (Ottesen and Strand, 1996), development of dark pigmentation on the blind side (hypermelanosis) (Ottesen and Strand, 1996; Iwata and Kikuchi, 1998; Kang and Kim, 2013), higher prevalence of lesions (Ottesen and Strand, 1996), skin abnormalities (Ottesen and Strand, 1996) and a higher occurrence of diseases (McVicar and White, 1982).

Many studies on the preference and the effect of different substrates on flatfish have been published. Although they prefer sandy substrates where they can bury (Ellis et al., 1997; Gibson and Robb, 2000; Nasir and Poxton, 2001; Reig et al., 2010), this kind of background does not always improve growth or survival. In fact it's more difficult to keep it clean since uneaten food and faeces tend to accumulate on it, this fact resulting in a worse water quality (Ottesen and Strand, 1996; Ellis et al., 1997; Rodiles et al., 2005; Batzina and Karakatsouli, 2012). For this reason, the use of sand in commercial sole culture has been considered an obstacle to maintain the hygienic conditions and it is not a prerequisite for successful culture of sole (Howell, 1997).

Several authors have studied alternative substrates and surfaces to replace sand in flatfish cultures keeping an increased growth, improved welfare and reduced malpigmentation and lesions. Ottesen and Strand (1996) kept juveniles of Atlantic halibut (Hippoglossus hippoglossus) in tanks with silicone ridges. With the exception of a relatively high degree of hyperpigmentation, fish attributes were better in units with silicone ridges on the bottom (higher growth and lower prevalence of external skin lesions on the blind side) than in sand. Kang and Kim (2013) observed similar results keeping olive flounders (Paralichthys olivaceus) in three types of substrates (flat, embossed and gravel bottom). A tendency to a higher daily growth rate in embossed tank was found as well as a weak inhibition of malpigmentation. Most of these authors hypothesize that the rougher surfaces may have a therapeutic effect because they stimulate mucus production and remove dead cells from the skin (McVicar and White, 1982; Ottesen and Strand, 1996; Ottesen et al., 2007; Kang and Kim, 2013).

Reig et al. (2010) studied the preference of sole (Solea senegalensis) in a short period of time $(72 \mathrm{~h}$ ) for different substrates (sand, plastic and concrete) with different texture (rough and smooth) and color (light and dark). As expected, sole exhibited a clear preference for sand, no matter the texture and color. But from their results a predilection for one of the alternative substrate, plastic or concrete cannot be set categorically. The results of the rate of immobility showed that plastic was tried quite frequently by the soles, but they did not remain on it, while they stayed longer on concrete.
To study the fish welfare in sedentary species, like flatfish and particularly soles, their activity is a good indicator (Kristiansen et al., 2004; Duarte et al., 2009): a high activity level corresponds to abnormal activity and could therefore be taken as a sign of poor welfare (Ashley, 2007). Using this feature, Duarte et al. (2009) proposed an index obtained from image analysis to determine the level of flatfish activity, named the Image Processing Activity Index (IPAI). It enables an objective quantification of fish movements and is less labor-intense than other methods based on direct observation.

The aim of this study is to test the effect of three types of tank bottom surfaces, with different physical and chemicals characteristics, on growth, welfare and skin condition of Senegalese sole (Solea senegalensis). The welfare was studied using the Image Processing Activity Index or IPAI described by Duarte et al. (2009).

\section{Materials and methods}

\subsection{Experimental tanks and water quality}

The study was carried out in the facilities of the "Escola Superior d'Agricultura de Barcelona" at the "Universitat Politècnica de Catalunya BarcelonaTech". Nine small rectangular tanks (17 cm wide, $25 \mathrm{~cm}$ long and $5 \mathrm{~cm}$ water depth) were used. To ensure the same quality and quantity of water in all tanks, a specific pipe system was designed (Fig. 1). Each tank had a water inlet submerged at one end and a water outlet at the opposite end located $5 \mathrm{~cm}$ above the bottom in order to control the water depth. The total water flow, controlled by a rotameter, was equally distributed through the tanks with individual valves, adjusting the water flow rates Water flow and other culture conditions were measured daily and were as follow (mean $\pm \mathrm{SD}$ ): in each tank water exchange rate was $3 \mathrm{~h}^{-1}$, temperature $17.65^{\circ} \mathrm{C} \pm 0.69$, dissolved oxygen was kept over saturation, $162 \%$ sat \pm 39.08 at the inlet and $138 \%$ sat \pm 30.06 at the outlet (both parameters OxyGuard Handy Polaris, Portable DO Meter), salinity $37 \mathrm{ppt} \pm 1$ (ATAGO S10E Salt 0-10\%), pH at the inlet was $7.67 \pm 0.10$ and $\mathrm{pH}$ at the outlet was $7.69 \pm 0.09$ (Crison MultiMeter MM 41). The fish were subjected to a photoperiod of 12-h light: 12-h dark.

\subsection{Fish and fish sampling}

Ten individuals of Solea senegalensis were stocked in each tank and three replicates of each surface were displayed $(\mathrm{N}=30$ in each surface). Fish were acclimated to the experimental surfaces for one week. The average initial individual weigh of soles was $3.0 \mathrm{~g} \pm 1.2$ (mean $\pm \mathrm{SD}$ ) and the rearing density was $0.61 \mathrm{~kg} \mathrm{~m}^{-2} \pm 0.02$ (mean \pm SD). They were fed by hand with a commercial sole pellet diet (Skretting Gemma Diamond 1.5). A feeding ratio of $2 \%$ of their body mass per day was distributed from Monday to Friday, except on sampling days. Fish were maintained under experimental conditions for 60 days.

Mortality per tank was checked every day. To avoid differences in sole growth and behavior due to different rearing densities between tanks, each dead fish was replaced by another one. The new ones were not used to estimate growth. To equal the number of fish in the three treatments, the results of 13 individuals for each surface tested were used. When more fish survived, 13 of them were randomly chosen for each treatment.

Every two weeks all fish were anesthetized (2-phenoxyetanol solution, $0.4 \mathrm{ml} \mathrm{L}^{-1}$ ) to be sampled. They were individually placed, with a ruler next to it, in a white tray, with enough seawater to cover the fish. The tray was placed over a light table to enhance the fish edge contrast. They were photographed using a digital camera (Nikon Coolpix P6000, $4224 \times 3168$ pixel of image resolution) and the blind side was 


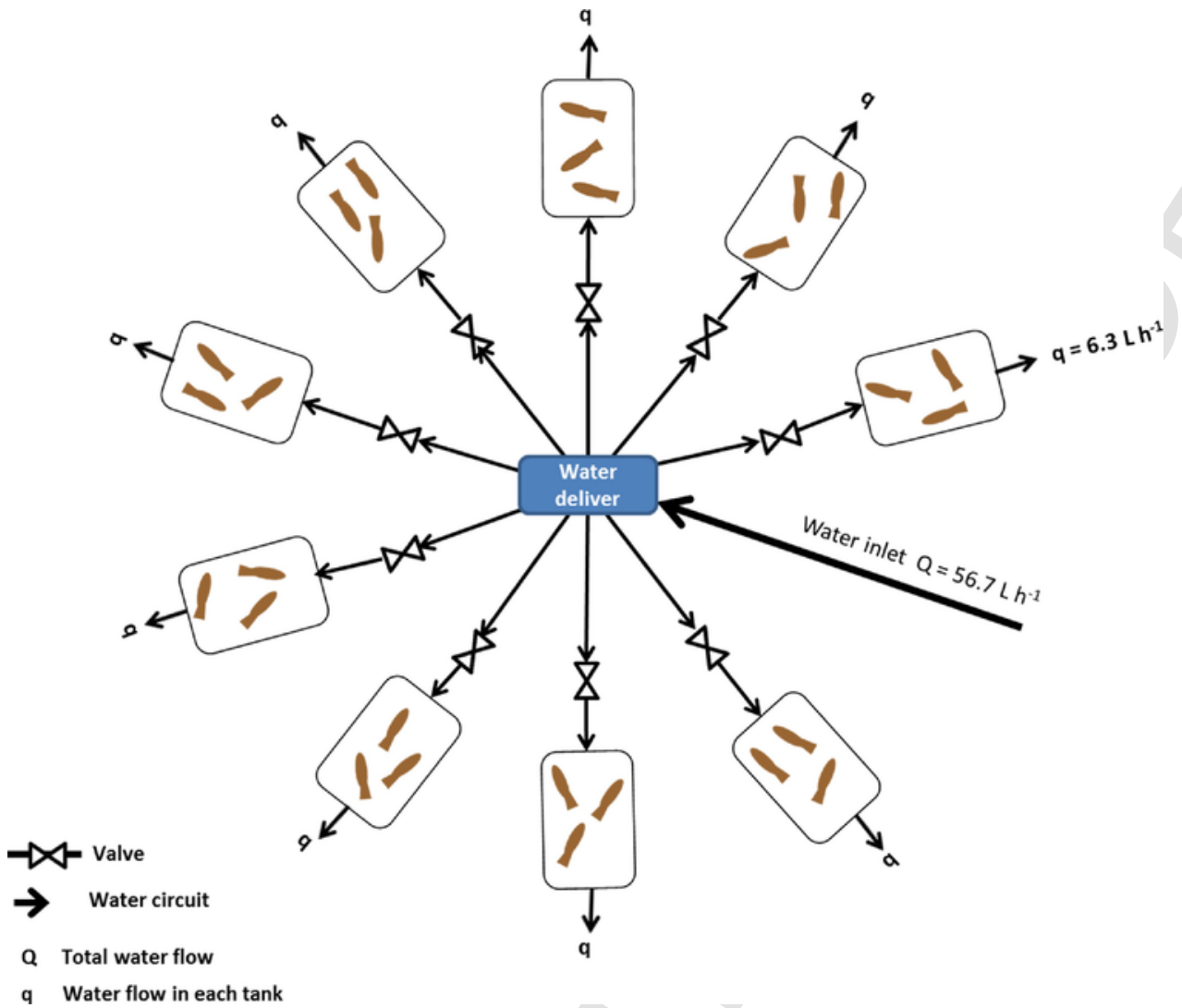

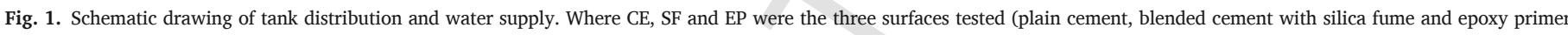
respectively) (10 fish per tank)

scanned individually to visualize any pigmentation on this area. Both images were used in order to morphologically identify each fish. Under experimental conditions, with few individuals, soles may be individually identified by digital images, avoiding marking. The following characteristics were used: (1) overall body shape, (2) shape and deviations of the caudal and pectoral fins, (3) other irregularities in fins and (4) pigmentation patterns (albinism and pseudoalbinism on the ocular side, and hypermelanosis on the blind side) (Fig. 2).

After that, fish were weighed to calculate the individual SGR (Specific Growth Rate) (\%) (Eq. (1)).
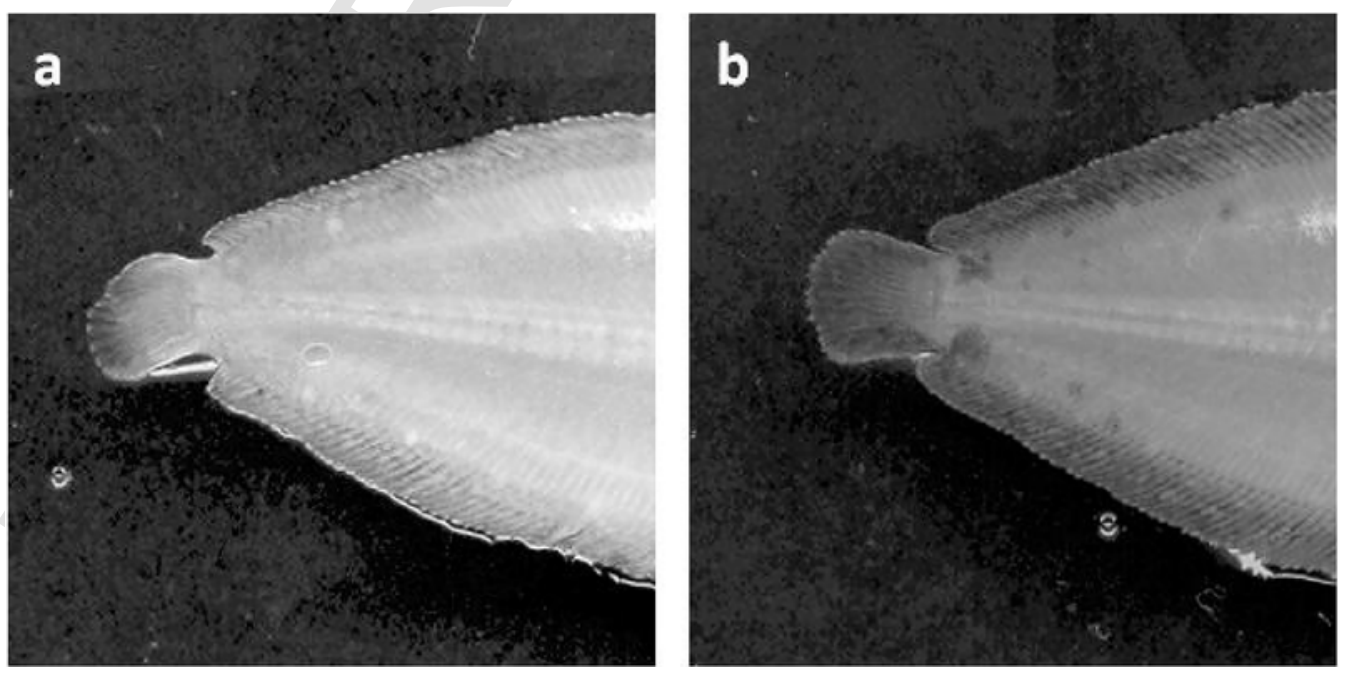

Fig. 2. Examples of characteristic (a) caudal fin shape and (b) pattern of pigmentation of blind side used for the morphological identification.

$$
S G R(\%)=\left[\frac{\left(\operatorname{Ln} W_{f}-\operatorname{Ln} W_{i}\right)}{t}\right] \times 100
$$

Where $W_{f}$ and $W_{i}$ were the final and initial fish weight and $t$ was the number of rearing days

Images of ocular side were also used to quantify the degree of fin erosion. All distances in the images were converted to centimeters using a scaling factor obtained from the ruler placed next to fish. Total area of fish, with fins, was measured using image analysis software 
(Image ProPlus). The area of body without fins (caudal, dorsal and anal) was obtained manipulating the images to remove them (Merino, 2004). The area of fins were calculated and used to obtain the fin factor by a modified equation of Kindschi (1987) with trout (Eq. (2)).

Fin factor $(\%)=\frac{\text { Fin area }}{\text { Total fish area }} \times 100(2)$

\subsubsection{Measurement of pigmented area on the blind side}

With the scanned images of the blind side, the total area of this side, excluding the fins, and the pigmented area were measured with image analysis software (Image ProPlus). Thus the percentage of pigmented area was estimated. It was considered that there was pigmentation when the percentage of pigmented area was above $1 \%$ of the blind side.

\subsection{Flatfish activity measurement}

To determine the level of flatfish activity as a measurement of welfare, the Image Processing Activity Index (IPAI) described by Duarte et al. (2009) was used.

\subsubsection{Image acquisition}

Recordings were made using the digital camera placed above the tanks. They were carried out 36 days after the beginning of the experiment to guarantee fish acclimation; they were made at light hours and after the feeding time. From 12:30 h to 13:20 h one image was recorded every $30 \mathrm{~s}$ in each tank, giving a total of 300 images per treatment. The shutter speed and aperture of diaphragm were fixed manually for each tank.

\subsubsection{Digital image analysis}

Recorded images were converted into 8-bit gray scale images ranging in pixel intensity from 0 to 256 . Image subtraction of two consecutive frames, $f$ and $h$, was done to obtain a "difference frame" $g$ with pixel intensity for each point $(x, y)$ calculated as shown in Eq. (3) (Duarte et al., 2009):

$g(x, y)=f(x, y)-h(x, y)+127$

The "difference frame" showed only the differences between two consecutive frames due to fish movement (Fig. 3a). In the absence of fish activity, no differences between frames would be found and the intensity of all pixels (IP) in the image would be IP $=127$ (Fig. 3b).

There could be some differences in pixel intensity between frames due to slight alterations in fish pigmentation, either caused by fish stress or to lighting differences produced by water surface movements. Taking these differences into account, pixel intensities that differed slightly from 127 should not be attributed to fish movement. Therefore, IP values which could be found without fish activity would be in
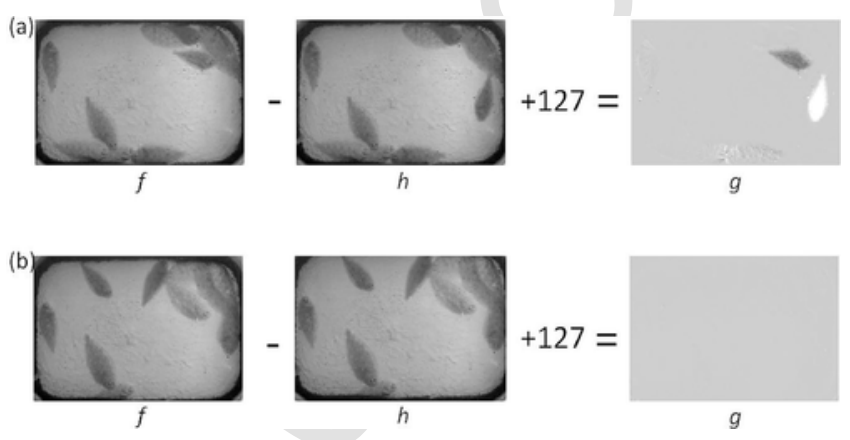

Fig. 3. Image subtraction on a new frame $g$ of two consecutive frames $f$ and $h$ : (a) some fish movement in the interval between frames and (b) no moving fish in the interval. the range IP $=127 \pm \alpha$, where $\alpha$ was a value of pixel intensity that must be determined experimentally, for each tank, subtracting two consecutive images without movement and including less than $0.5 \%$ of pixels.

In the recorded intervals, each "difference frame" will give an IPAI-frame value $\left(\mathrm{IPAI}_{f}\right.$ ), which will be the percentage of pixel intensities outside the range $127 \pm \alpha$ (Eq. (4)):

$I P A I_{f}=\left(\frac{P_{A}}{P}\right) \times 100$

Where $P$ was the total number of pixels and $P_{A}$ the number of pixels outside the range $127 \pm \alpha$. For each surface a total of 300 IPAI values were obtained. In order to determine the value of $\alpha, 12$ pairs of two consecutive images for each substrate in which no fish activity was observed were selected. IPAI values of these images were only attributable to changes in lighting due to water surface movements or to changes in fish pigmentation due to stress.

\subsection{Experimental tank bottom surfaces}

Three surfaces were used, considering their suitability for commercial aquaculture: plain cement (CE), cement blended with a silica fume (SF), and cement structure completely covered with epoxy primer (EP).

The main characteristics of materials were the following:

(a) Plain Cement (CE): made with cement and sand with the usual 1:3 dosage. The cement was Portland type I according to the UNE-EN 197-1:2000 (CEMEX company). High purity quartz sand was chosen, usually intended for the manufacture of glass, (Sibelco SA company) with $32 \mathrm{DU}$ particle size $(32 \mu \mathrm{m})$. The water Binder Ratio (WBR) was 0.35 . It was highly alkaline and with a $\mathrm{pH}=13.5$.

(b) Cement blended with a silica fume (SF): a mix of the same cement used in Plain Cement surface with $10 \%$ of silica fume substitution (Sika ${ }^{\circledR}$ Fume S-92-D, particles less of $0.1 \mu \mathrm{m}$, amorphous silica content $>90 \%$ ) and the same percentage of sand was used. The WBR in this surface also was 0.35 . Silica fume admixture is used to increase the durability and strength of concrete, improve abrasion resistance as well as reduce the permeability of mortar (Product Data Sheet, Edition 04/2006). Moreover, the usual high pH of plain cement, roughness and porosity are reduced.

(c) Epoxy coat (EP): an identical basis of cement used in Plain Cement surface treatment, was covered with two layers of epoxy primer (Ti$\tan$ Yate) used for submerged surfaces and for marine environments. An inert surface was obtained with no effect on the $\mathrm{pH}$ of water, lower roughness than plain cement and no porosity.

\subsubsection{Tank bottom surface characterization}

To characterize the properties of the three substrates chemical and physical determinations were done.

2.4.1.1. Chemical properties Chemical composition of plain cement (CE) and cement blended with silica fume (SF) were analyzed by the examination of their internal microstructures images conducted by using a JEOL JSM-6300 scanning electron microscopy (SEM). Attached to it, a LINK ISIS-200 Energy Dispersive X-ray analysis (EDX) was used obtaining their chemical composition.

To measure the pozzolanic reaction, a Differential Scanning Calorimetre (DSC) was used. DSC measures enthalpy changes in samples due to changes in their physical and chemicals properties as a function of temperature or time. The reaction can be deduced either by observing an increase in the amount of calcium silicate hydrate or by observing a decrease of calcium hydroxide (Go et al., 2010). 


\subsubsection{Physical properties}

2.4.1.2.1. Roughness The roughness is a quantitative measure of the marks produced by the creation of the surface and other factors such as the structure of the material. These marks are the ridges by which the surface differs from a perfect smooth line or plane.

The surface profiler used was a Form TalySurf Plus (Taylor-Hob$\left.\operatorname{son}^{\circledR}\right)$. To evaluate the different roughness of each type of substrate, the surface roughness average $(R a)$ was measured throughout a length of $5 \mathrm{~cm}$ for each substrate. $R a$ is the most used international parameter of roughness and mathematically, it is the arithmetic average value of the absolute (or modulus of the) departure of the profile from the reference line throughout the sampling length (Taylor-Hobson, 2011).

2.4.1.2.2. Porosity The percentage of porosity $(\phi)$ of plain cement and cement blended with silica fume surfaces were calculated by the pore volume $\left(V_{p}\right)$ and bulk volume $\left(V_{b}\right)$ (Eq. (6))

$\phi(\%)=\frac{V_{p}}{V_{b}} \times 100$

The sample was immersed in water during 21 days and the weight of saturated sample was obtained $\left(W_{\text {sat }}\right)$. Then, the sample was dried in the oven at $60^{\circ} \mathrm{C}$ to constant weight and dry weigh was registered $\left(W_{d r y}\right)$. The weight of water retained in the pores was obtained $\left(W_{s a t}-W_{d r y}\right)$ and converted to volume $\left(V_{p}\right)$ using the water density. The bulk volume $\left(V_{b}\right)$ was determined weighing the water displaced by saturated sample submerged in water.

Porosity equal to zero was attributed to the epoxy coated surface because it covered the porosity of the cement.

2.4.1.2.3. Bending and compressive strength In order to compare the mechanical characteristics and to quantify the improvement with the silica fume admixture in front of plain cement, both flexural and compressive tests were performed. A universal testing machine equipped with a maximum load cell of $3 \mathrm{kN}$ for bending test and $300 \mathrm{kN}$ for compression test were used. The flexural tests were performed with a three-point bending configuration on specimens of $40 \times 40 \times 160 \mathrm{~mm}$ at load speed of $50 \pm 10 \mathrm{~N} \mathrm{~s}^{-1}$. The compressive tests were performed on cubic specimens of $40 \mathrm{~mm}$ edge. The load speed for the compression test was $2400 \pm 200 \mathrm{~N} \mathrm{~s}^{-1}$. Both flexural and compressive tests were performed following the UNE-EN 196-1:2005 standard (AENOR, 2005).

\subsection{Statistical analysis}

\subsubsection{Statistical analyses were performed using SPSS 19.0 for windows}

Differences in the increment from the initial and the final sampling of fin erosion, pigmentation on blind side of soles kept on different surfaces, and the mean roughness of surfaces tested were determined by a one-way ANOVA once normality and homogeneity of variance were verified by Shapiro-Wilk test $(p>0.05)$ and Levenes's $F$-test $(p>0.05)$ respectively. When significant differences were detected $(p<0.05)$, Tukey's test was used to determine treatment group differences.

In the Specific Growth Rate distribution, normality of data was verified by Shapiro-Wilk test $(p>0.05)$ but heterogeneity of variances existed (Levenes's $F$-test $p<0.05$ ) and therefore a robust Welch's test was applied to check differences between treatments. Differences were considered significant when $p<0.05$, then Game-Howell's test was used to establish differences among groups.

A Kolmogorov-Smirnov test was used to assess the normality of the IPAI values obtained at each surface $(\mathrm{N}=300)$. Due to the no normality of the data $(p<0.05)$, non-parametric Kruskal-Wallis single factor analysis of variance by ranks was used. Subsequent comparisons between surfaces were carried out when significant differences were detected $(p<0.05)$ using the Mann-Whitney $U$ test, followed by a Bon- ferroni adjustment of probabilities to determine where the differences were $(p<0.01)$.

Frequency histograms of IPAI obtained in each surface were used to illustrate the activity of soles and the whole set of ordered data was divided into four equal parts or quartiles.

\section{Results}

\subsection{Fish}

\subsubsection{Growth measurements}

The average of the individual Specific Growth Rate (SGR\% \pm SD) is plotted in Fig. 4. The highest SGR was registered by the fish kept on the surface containing silica fume (SF) $(0.49 \% \pm 0.25)$ which was significantly higher $(p<0.05)$ than the SGR achieved by the fish kept on the epoxy coated surface (EP) $(0.26 \% \pm 0.10)$. There were no significant differences ( $p>0.05$ ) between the specific growth rate achieved by the fish kept over the plain cement surface (CE) $(0.31 \% \pm 0.19)$, and those kept on the other two, SF and EP.

\subsubsection{Fish activity level and welfare}

The IPAI value, described by Duarte et al. (2009), was determined to show the level of fish activity.

Firstly, $\alpha$ was determined experimentally for the range of pixels in which no movement of fish was recorded (IP $=127 \pm \alpha$ ). The $\alpha$ for plain cement (CE), cement blended with a silica fume (SF) and epoxy primer painted surface (EP) were 7, 10 and 8 respectively. The results of IPAI are shown in Fig. 5.

The IPAI ranges from 0 to 100 , the higher the value of IPAI, the higher the level of activity. Significant differences were found between all types of surfaces $(p<0.05)$ and between all pairs of them $(p<0.01)$.

Quartiles indicated that the lowest fish activity occurred in the cement with silica flume (SF), where the $25 \%$ of lower IPAI values obtained were below than $2.8\left(Q_{1}\right)$. Values obtained in the plain cement (CE) and the epoxy treated surface (EP) were 5.3 and 6.4, respectively. In the same way, the lowest $Q_{2}$ or median was registered in SF (6.4 in front of 9.5 and 12.1 in CE and EP respectively), showing a lower level of activity in this surface compared with the other two.

\subsubsection{Skin condition}

In all tank bottom surfaces tested, the mean value of the fin factor increased, showing that a fin regeneration was observed (Fig. 6) $($ mean $\pm \mathrm{SD} ; \quad \mathrm{CE}=1.77 \% \pm 3.51 ; \quad \mathrm{SF}=1.44 \% \pm 3.24$;

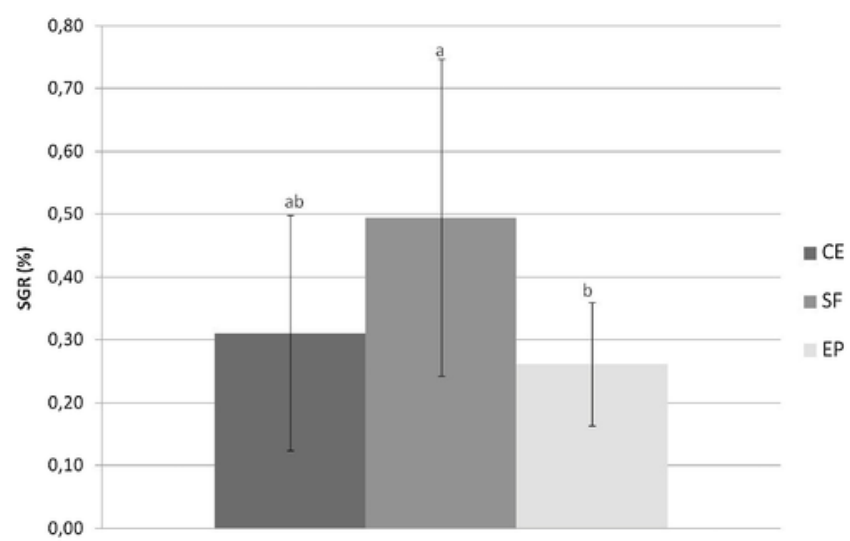

Fig. 4. Average of $S G R \% \pm S D(N=13)$ registered by the fish kept on the different surfaces tested $(\mathrm{CE}=$ plain cement, $\mathrm{SF}=$ cement with silica fume and $\mathrm{EP}=$ surface covered with epoxy primer). Statistically significant differences $(p<0.05)$ between groups are represented with different letters. 

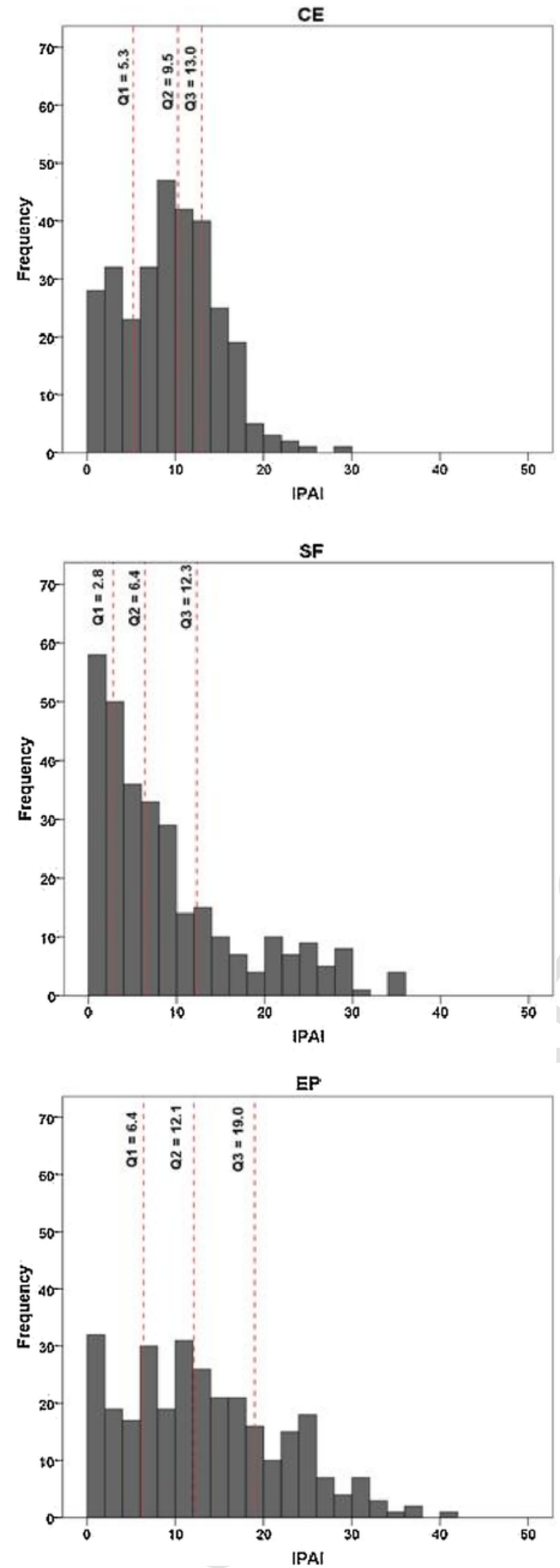

Fig. 5. Frequency histograms of IPAI determined in CE, SF and EP surfaces $(\mathrm{N}=300)$. Dotted line are located in the quartile $25\left(Q_{1}\right)$, quartile 50 or median $\left(Q_{2}\right)$ and quartile 75 $\left(Q_{3}\right)$.
$\mathrm{EP}=0.85 \% \pm 2.01$ ) but no statistically significant differences were observed between three surfaces.

No abnormalities in the ocular side pigmentation were detected, but a slight hypermelanosis on the blind side was observed in some individuals from the beginning of the experiment. This consisted of small patches of darker color in the lower half of the fish.

At the end of the study, no significant differences $(p>0.05)$ were found in hypermelanosis compared with the beginning of the experiment.

\subsection{Tank surface materials}

\subsubsection{Chemical properties}

The images of the microstructures of the specimen of plain cement (CE) (Fig. 7a) and the cement blended with silica fume (SF) (Fig. 8a) are shown. In the last one, a smaller presence of pores (Fig. 8a number 2) and large areas of calcium silicate hydrated (CSH) precipitate (Fig. 8a number 6) were observed. This fact with the lower amount of calcium and higher of silica in SF substrate observed in the graph of Energy Dispersive X-ray analysis (Fig. 8b) in front of CE (Fig. 7b), supported the pozzolanic action of added silica fume.

The sample coated with epoxy primer (EP) wasn't analyzed because it was an amorphous material without microstructures and the matrix used was no relevant.

The Fig. 9 illustrates the Differential Scanning Calorimetre (DSC) test of the CE and SF substrates. In the DSC test exothermic peaks appeared. The peak in the interval from 25 to $250{ }^{\circ} \mathrm{C}$ corresponded to the liberation of physical bound water from pores and also to dehydration reaction to loss of water from calcium silicate hydrate gel (CSH). The next peak was around $480{ }^{\circ} \mathrm{C}$ and it was related to the dehydration of calcium hydroxide. When reaching the temperature of $750-770{ }^{\circ} \mathrm{C}$, the calcium carbonate decomposition was initiated (Trník et al., 2014).

The peak of the CSH for the cement containing silica fume was higher than in the plain cement. This was mainly due to the pozzolanic reaction of silica to calcium hydroxide forming larger amount of CSH and for this reason, the peak of calcium hydroxide in the SF was clearly lower. On the other side, the third peak of calcium carbonate was practically equal in both mortars. This indicated that calcium carbonate was not involved in the reaction and the calcium hydroxide decreased by the pozzolanic action of silica, reducing the alkalinity of plain cement.

The higher alkalinity of plain cement was not reflected in a $\mathrm{pH}$ increase in the water column but it could be assumed that changes in the volume of water immediately in contact with the blind side of the fish occurred.

\subsubsection{Physical properties}

The roughness of the three types of surfaces is represented in Fig. 10. A significant difference between roughness of plain cement (CE) and the other two treated surfaces, silica fume (SF) and epoxy primer (EP) $(p<0.05)$ was observed. But no significant differences $(p>0.05)$ were registered between roughness of SF and EP surfaces.

The measured porosity of CE and SF were 17.71 and $13.67 \%$, respectively, and corroborate the lower porosity in SF surface observed in the images of microstructures (Figs. 7a and 8a). The EP surface was considered a non-porous material. The bending stress calculated for the SF was $44 \%$ higher than the calculated for CE surface. In the same way, the resistance measured by a compression test was $73 \%$ higher in SF surface. 

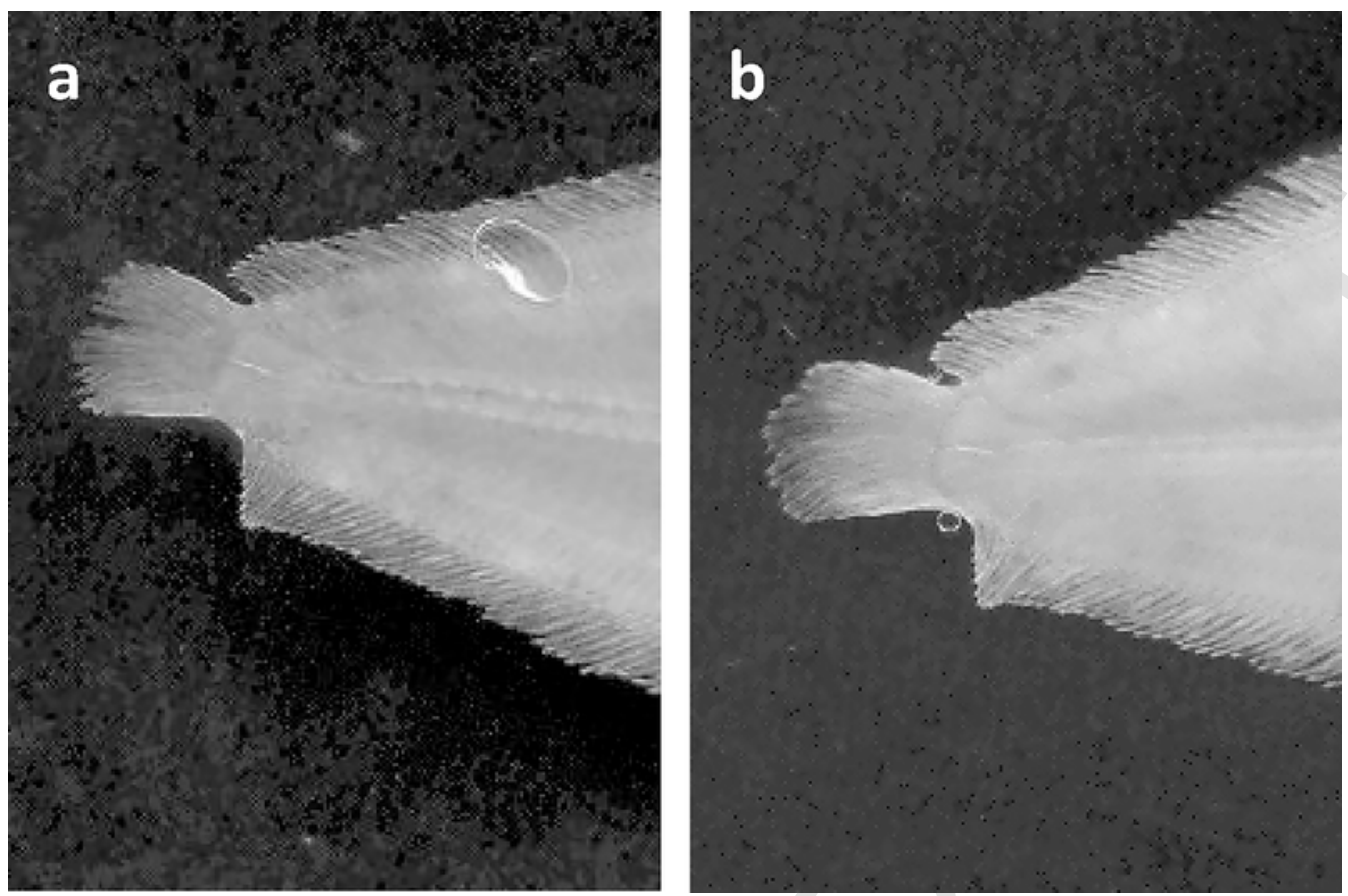

Fig. 6. Example of caudal fin regeneration of one fish kept on plain cement (CE) surface from the beginning of the experiment (a), until the end (b).

\section{Discussion}

\subsection{Relationship between growth and activity level of the fish}

The results obtained here with Senegalese soles showed, generally, that when the immobility index or IPAI was lower, the specific growth rate was higher. Probably fish found better well-being conditions resulting in a higher performance in terms of growth in the cement blended with silica fume (SF). Fish kept on this surface presented an $89 \%$ higher SGR than the one performed by the fish kept on the epoxy coated surface (EP) where the IPAI was the highest registered. In EP, the first quartile of IPAI values was lower than 6.4 in front of 2.8 in SF surface.

Changes in behavior of cultured fish can be useful to measure the welfare and to indicate a poor health (Broom, 2008; Conte, 2004; Ashley, 2007; Duarte et al., 2009). In the specific case of flatfish, that have been described as sedentary species (Gibson, 2005), the lower the activity, the higher the welfare. Kristiansen et al. (2004) with Atlantic halibut (Hippoglossus hippoglossus), observed that surface swimming behavior was negatively correlated with growth rate and described this behavior as an indicator of suboptimal growth that affects welfare.

\subsection{Effect of tank surface on fish}

When comparing the two most usual aquaculture tanks surfaces, cement and an epoxy coated surface, which is inert and no porous, no statistical differences on fish growth were found. Nevertheless, differences in the activity level were observed between fish kept on them. Inert and no porous surfaces seem to offer a more uncomfortable environment to soles. In the same way, Reig et al. (2010) also registered higher mobility of soles kept on plastic in front of fish kept on concrete.

On the other hand, with the addition of silica fume to plain cement, the environmental conditions seem to have improved, promoting a better growth and welfare represented by lower IPAI.
Some characteristics distinguish the surfaces tested and probably promote the differences. Firstly, the CE and SF surface are porous but the porosity of EP have been considered null, this feature may have affected the welfare and growth of fish because this surface is strongly different from any surface present in the marine environment and fish may have reacted negatively. It can also be related with the effect of the null porosity on the adhesion forces. Surfaces with no porosity can increase the total force required to lift the head early enough in the rapid take-offs, when flatfish leave the bottom (Brainerd et al., 1997). Take-off is opposed by water viscosity and a suction pressure develops under the fish making it more difficult to leave the seabed (Gibson, 2005).

The higher $\mathrm{pH}$ of cement, around 13, is remarkable due to the effect in the water retained in their pores, therefore in direct contact with the flatfish. Environmental $\mathrm{pH}$ affects the toxicity of ammonia; higher values of $\mathrm{pH}$ promote a higher concentration of the un-ionized ammonia form $\left(\mathrm{NH}_{3}\right)$ which is toxic for fish (Thurston et al., 1981; Haywood, 1983; Tomasso, 1994). When the concentration of $\mathrm{NH}_{3}$ is high in water it rapidly diffuses across the gill membrane into the blood reducing the fish growth (Thurston et al., 1981; Haywood, 1983; Tomasso, 1994; Person-Le Ruyet et al., 1997). The pozzolanic reaction developed by the presence of silica and calcium hydroxide in the cement, along the time, decreases the $\mathrm{pH}$ and alkalinity of the substrate (Toutanji and Bayasi, 1999), which decreases the effect that it may have on the water filling the pores directly in contact with soles.

Additionally the high alkalinity of cement could damage the skin of soles (EU, 2008), but in the present work, the analysis of images of fish did not show any injury on the sole skin. The presence of skin lesions are highly dependent on the length of time that a fish is exposed to a particular substrate (Ottesen et al., 2007). Probably, the fact that no lesions have been observed in the present work could be attributable to its relatively short duration (60 days); a longer trial would be needed to provide sounder results.

Differences in malpigmentation of blind side were neither found between the soles kept on different surfaces. This is in agreement of the results reported by Dinis et al. (1999) and Morais et al. (2014) that only found a $5 \%$ of hatchery reared sole (Solea senegalensis) with pig- 

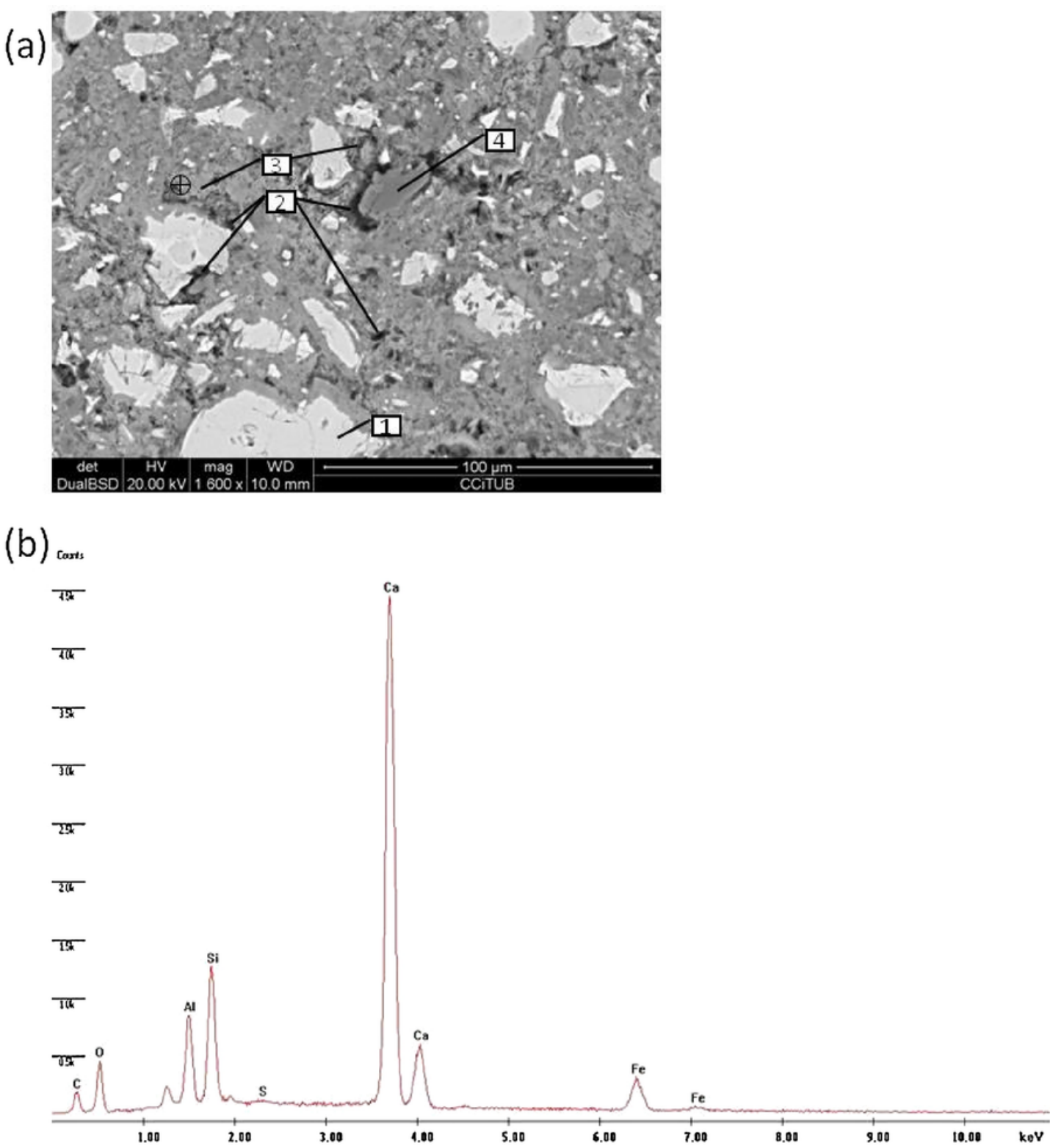

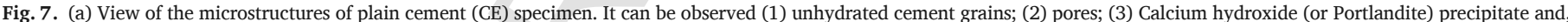

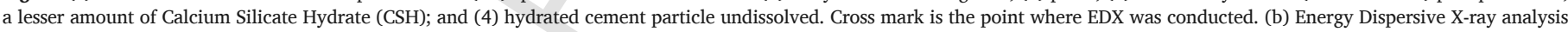
(EDX) corresponding to CE sample.

ment disorders, considering that pigmentation abnormalities are not a problem in sole unlike other species of flatfish.

Moreover, the fish have not shown fin erosion, but, on the contrary, some fin regeneration has been observed in fish kept on all surfaces tested. Other factors may have been involved in this phenomenon such as the low rearing density used here $\left(0.61 \mathrm{~kg} \mathrm{~m}^{-2}\right)$ that might have played a more important role than the surface type (Kindschi, 1987; Rafatnezhad et al., 2008; Cañon Jones et al., 2011).

In terms of roughness, previous studies of flatfish found that it improves growth (McVicar, 1987; Ottesen and Strand, 1996; Ottesen et al., 2007; Kang and Kim, 2013) because the abrasive effect could have stimulated mucus production and assisted in removal of dead cells and other debris from the skin. This may be relevant in the avoidance of secondary skin infections (Ottesen and Strand, 1996). Although the three surfaces tested here presented some roughness, it is clearly higher in CE surface, which is not the best surface for sole welfare. Probably this parameter is more negatively affected by their highest porosity be- cause food debris and faeces may have accumulated among the pores of the cement, so cleaning and disinfection becomes more difficult and hygienic conditions become compromised.

\subsection{Influence of silica fume addition on tank construction and management}

In reference to the tank construction, silica fume admixture presents some advantages like improvement of the resistance of concrete to chloride penetration (Shi et al., 2012; Tadayon et al., 2016), among others. Chloride ingress is the most deteriorating factor for reinforced concrete structures exposed to marine environmental due to steel corrosion which lead to reduction in the strength, serviceability and esthetics of the structures (Shi et al., 2012).

Moreover, in flatfish aquaculture, there is an increasing tendency to use multi-layered shallow raceway systems to reduce the space needed (Øiestad, 1999; Kamstra et al., 2012). Cement blended with silica fume 


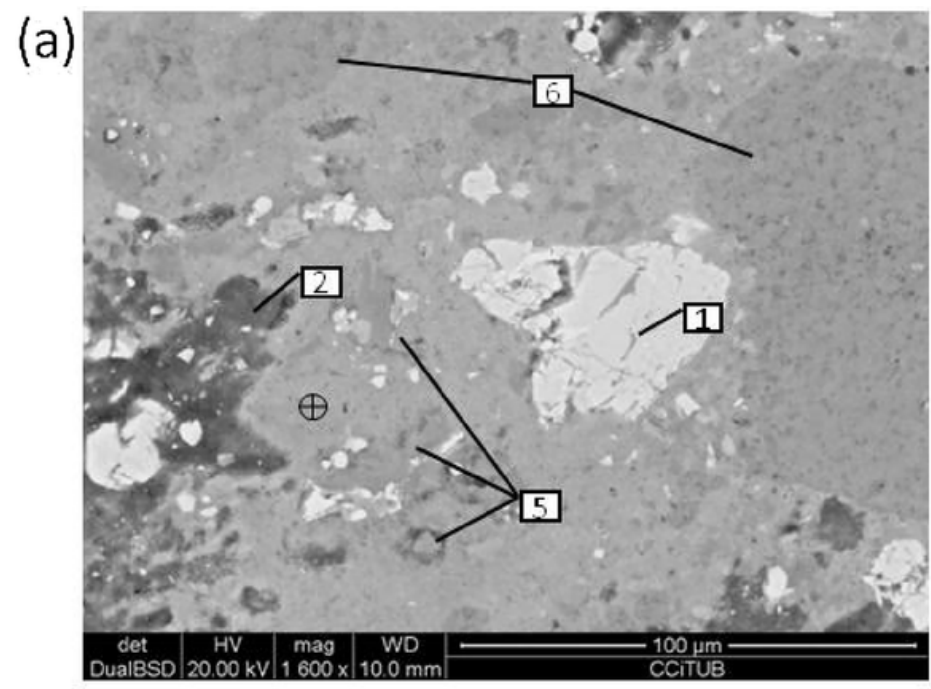

(b)

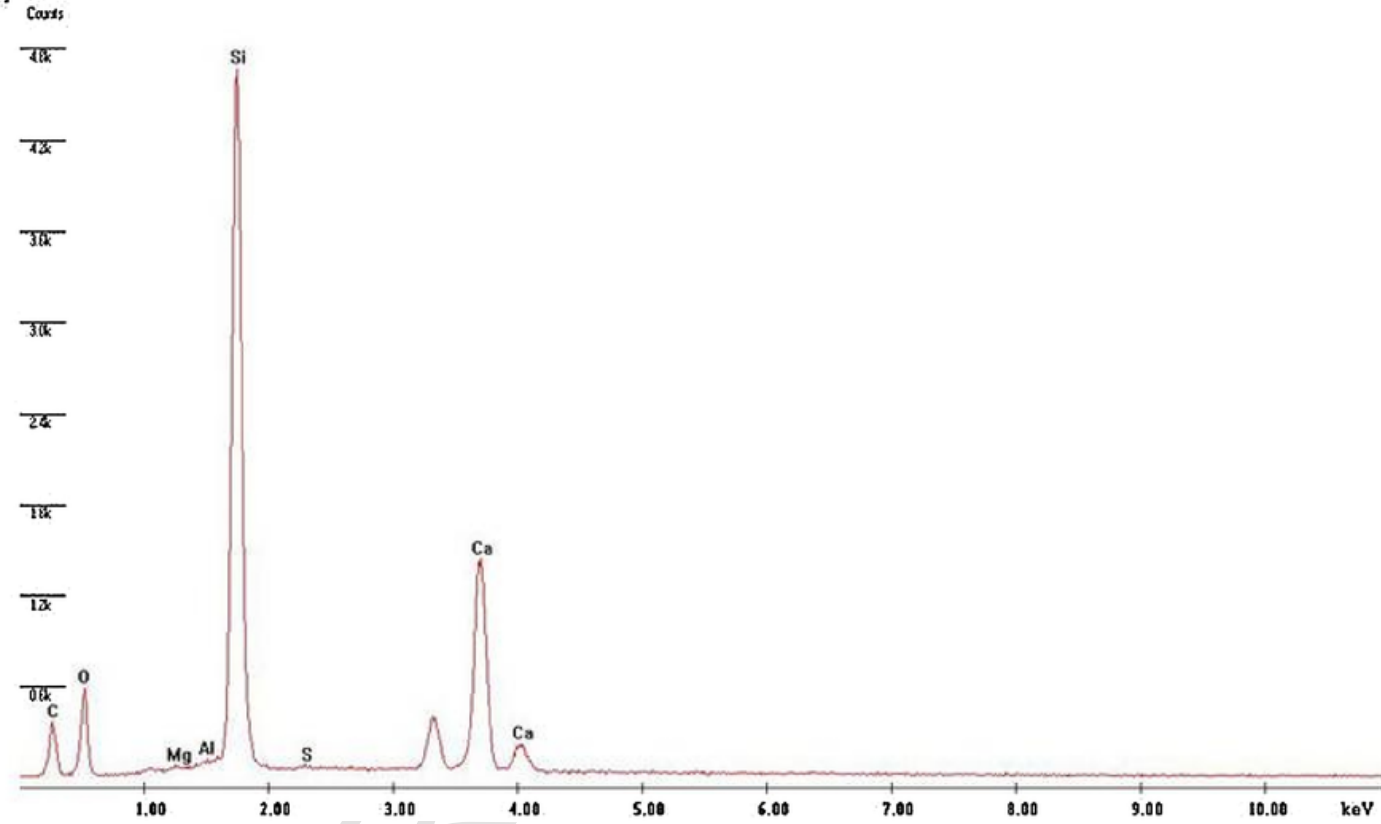

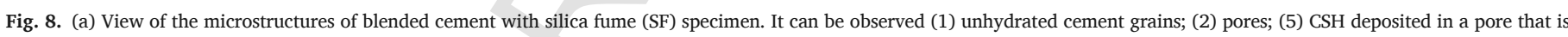
still to be filled; and (6) areas of CSH precipitate. Cross mark is the point where EDX was conducted. (b) Energy Dispersive X-ray analysis (EDX) corresponding to SF sample.

can be easily adapted to this system because it has a higher strength and durability than plain cement. These characteristics allow constructing lighter tanks and structures and due to its versatility, they could be constructed as prefabricated units. In addition, the use of silica fume reduces the material cost, greenhouse gas emissions and landfill waste since it is an industrial byproduct (Shi et al., 2012).

Blending the plain cement with silica fume also offers better results regarding the tank management. Silica admixture makes it a lesser porous cement, where faeces and uneaten food may accumulate, and facilitates the operations of cleaning and disinfection.

\section{Conclusions}

In the work here presented the influence of different tank construction materials on growth, welfare and skin condition on Senegalese soles (Solea senegalensis) was tested.

The high $\mathrm{pH}$ of plain cement (around 13) didn't modify perceptively the main $\mathrm{pH}$ of water of the tank, but probably it increases the
$\mathrm{pH}$ of water retained in tank bottom surface porous in direct contact with flatfish skin. When plain cement is blended with silica fume a reduction of alkalinity, $\mathrm{pH}$ and porosity occurred. Most likely this improvement is related with the lower level of activity registered, which in flatfishes is usually related with greater welfare and therefore with higher growth.

Contrarily, the null porosity of the epoxy coated surface seems to affect negatively the well-being of soles, which probably perceive it as a foreign material and changes more frequently their location in the tank resulting in a detrimental effect on growth.

The observation of fish skin conditions and fin erosion did not allow identifying differences between the fish cultured on the three evaluated surfaces.

The characteristics that the silica fume provides to standard cement promote a higher fish performance, as well as a better mechanical behavior allowing the construction of lighter tanks, which is an advan- 


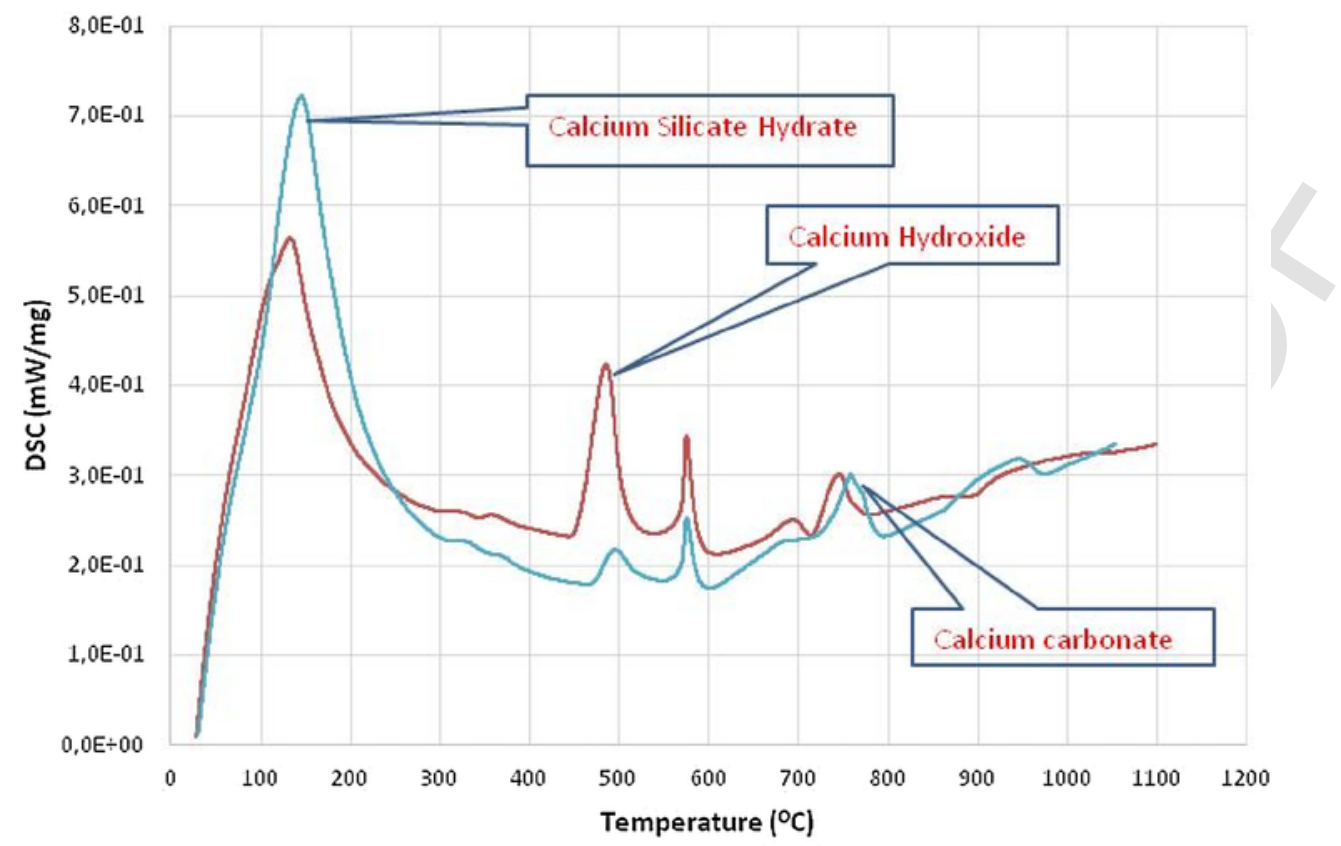

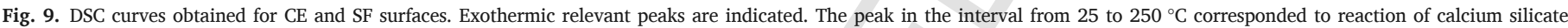
hydrate gel, around $480{ }^{\circ} \mathrm{C}$ corresponded to calcium hydroxide dehydration, and the peak around 750 and $770{ }^{\circ} \mathrm{C}$ to decomposition of calcium carbonate.

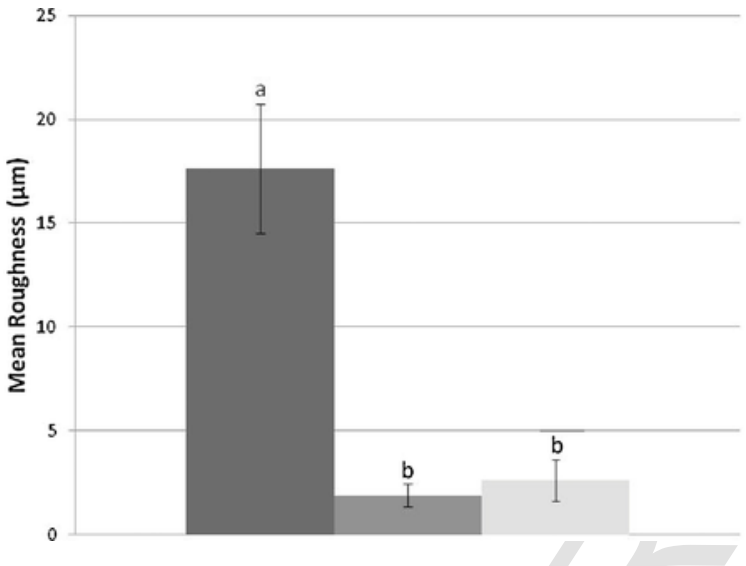

Fig. 10. Average $( \pm S D)$ roughness of the three surfaces tested $(C E, S F$ and $E P)(N=3)$ Statistically significant differences between groups at the 0.05 level are shown with different letters.

tage for flatfish facilities especially in multilayered shallow raceway systems.

These results emphasize the importance of the choice of the suitable materials for the construction of flatfish intensive aquaculture. These must combine good mechanical characteristics with beneficial effects for the welfare and growth of animals.

\section{Acknowledgement}

This work was funded by Spanish Ministerio de Educación y Ciencia (AGL2009-1655 and AGL2013-41868-R).

\section{References}

Øiestad, V., 1999. Shallow raceways as a compact, resource maximizing farming procedure for marine fish species. Aquac. Res. 30, 831-840.

AENOR, 2005. UNE-EN 196-1:2005. Methods of Testing Cement — Part 1: Determination of Strength. AENOR.
Ashley, P.J., 2007. Fish welfare: current issues in aquaculture. Appl. Anim. Behav. Sci. 104, 199-235.

Batzina, A., Karakatsouli, N., 2012. The presence of substrate as a means of environmental enrichment in intensively reared gilthead seabream Sparus aurata: Growth and behavioral effects. Aquaculture 370-371, 54-60.

Bosakowski, T., Wagner, E.J., 1995. Experimental use of cobble substrates in concrete raceways for improving fin condition of cutthroat (Onchorhynchus clarki) and rainbow trout (O. mykiss). Aquaculture 130, 159-165.

Brainerd, E.L., Page, B.N., Fish, F.E., 1997. Opercular jetting during fast-starts by flatfishes. J. Exp. Biol. 200, 1179-1188.

Broom, D.M., 2008. Animal welfare: concepts and measurements. J. Anim. Sci. 69, 4167-4175.

Cañon Jones, H.A., Noble, C., Damsgård, B., Pearce, G., 2011. Social network analysis of the behavioural interactions that influence the development of fin damages in Atlantic salmon parr (Salmo salar) held at different stocking densities. Appl. Anim. Behav. Sci. 133, 117-126.

Chung, J.Y., Kowal-Vern, A., Latenser, B.A., 2007. Cement-related injuries: review of a series, the National Burn Repository, and the prevailing literature. J. Burn Care Res. 48 , $827-834$.

Conte, F.S., 2004. Stress and the welfare of cultured fish. Appl. Anim. Behav. Sci. 86, 205-223.

Dinis, M.T., Ribeiro, L., Soares, F., Sarasquete, C., 1999. A review on the cultivation potential of Solea senegalensis in Spain and Portugal. Aquaculture 176, 27-38.

Duarte, S., Reig, L., Oca, J., 2009. Measurement of sole activity by digital image analysis. Aquac. Eng. 41, 22-27.

EU, 2008. Regulation (EC) No. 1272/2008 of the European Parliament and of the Council on Classification, Labelling and Packaging of substances and mixtures. Off. J. Eur. Union L353, 1-1354.

Ellis, T., Howell, B.R., Hughies, R.N., 1997. The cryptic responses of hatchery-reared sole to a natural sand substratum. J. Fish Biol. 51, 389-401.

Gibson, R.N., Robb, L., 2000. Sediment selection in juvenile plaice and its behavioural basis. J. Fish Biol. 56, 1258-1275.

Gibson, R.N., 2005. The behavior of flatfishes. In: Gibson, R.N. (Ed.), Flatfishes Biology and Exploitation. Blackwell Publishing, Oxford.

Go, S.S., Chung, C.W., Struble, L., Lee, H.C., 2010. Pozzolanic activity of Hwangtoh clay Constr. Build. Mater. 24, 2638-2645.

Haywood, G.P., 1983. Ammonia toxicity in teleost fishes: a review. Can. Tech. Rep. Fish. Aquat. Sci. 1177, 1-35.

Howell, B., Pricket, R., Cañavate, P., Mañanos, E., Dinis, M.T., Conceição, L., Valente, L.M.P., 2011. Sole farming: there or thereabouts! a report of the 5th workshop on the cultivation of soles. Aquacult. Eur. 36, 42-45.

Howell, B.R., 1997. A re-appraisal of the potential of the sole, Solea solea (L.), for commercial cultivation. Aquaculture 155, 355-365.

Hoyle, I., Oidtmann, B., Ellis, T., Turnbull, J., North, B., Nikolaidis, J., Knowels, T.G., 2007. A validated macroscopic key to assess fin damage in farmed rainbow trout (Oncorhynchus mykiss). Aquaculture 270, 142-148.

Imsland, A.K., Foss, A., Conceição, L.E.C., Dinis, M.T., Delbare, D., Schram, E., Kamstra, A., Rema, P., White, P., 2003. Rev. Fish Biol. Fish. 13, 379-407. 
Iwata, N., Kikuchi, K., 1998. Effects of Sandy substrate and light on hypermelanosis of the blind side in cultured Japanese flounder Paralichthys olivaceus. Environ. Biol. Fishes 52, 291-297.

Jadhav, U., 2009. Aquaculture Technology and Environment. PHI Learning Pvt. Ltd., New Delhi, India.

Kamstra, A., Blom, E., Blonk, R., 2012. Design and economic performance of an innovative raceway system for sole (Solea solea). Aqua 2012. Book of European Aquaculture Society, Prague, (p. 538).

Kang, D.Y., Kim, H., 2013. Importance of bottom type and background color for growth and blind-side hypermelanosis of the olive flounder, Paralichthys olivaceus. Aquacult. Eng. 57, 1-8.

Kindschi, G.A., 1987. Method for quantifying degree of fin erosion. Progress. Fish-Culturist 49, 314-315.

Kristiansen, T.S., Fernö, A., Holm, J.C., Privitera, L., Bakke, S., Fosseidengen, J.E., 2004. Swimming behaviour as an indicator of low growth rate and impaired welfare in Atlantic halibut (Hippoglossus hippoglossus L.) reared at three stocking densities. Aquaculture 230, 137-151.

Latremouille, D.N., 2003. Fin erosion in aquaculture and natural environments. Rev. Fish. Sci. 11, 315-335.

McVicar, A.H., White, P.G., 1982. The prevention and cure of an infectious disease in cultivated juvenile dover sole, Solea solea (L.). Aquaculture 23, 213-222.

McVicar, A.H., 1987. Black Patch Necrosis of the skin of Solea solea (L.): the role of sand in prophylaxis and treatment. J. Fish Dis. 10, 59-63.

Merino, G., 2004. Bioengineering Requirements for the Intensive Culture of California Halibut (Paralichthys Californicus). University of California, Davis, (PhD).

Morais, S., Aragão, C., Cabrita, E., Conceição, L.E.C., Constenla, M., Costas, B., Dias, J., Duncan, N., Engrola, S., Estevez, A., Gisbert, E., Mañanós, E., Valente, L.M.P., Yúfera, M., Dinis, M.T., 2014. New developments and biological insights into the farming of Solea senegalensis reinforcing its aquaculture potential. Rev. Aquac. 6, 1-37.

Nasir, N.A., Poxton, M.G., 2001. Substratum preferences of juvenile flatfish. Cybium 25 (2), 109-117.

Ottesen, O.H., Strand, H.K., 1996. Growth development, and skin abnormalities of halibut (Hippoglossus hippoglossus L.) juveniles kept on different bottom substrates. Aquaculture $146,17-25$

Ottesen, O.H., Noga, E.J., Sandaa, W., 2007. Effect of substrate on progression and healing of skin erosions and epidermal papillomas of Atlantic halibut, Hippoglossus hippoglossus (L.). J. Fish Dis. 30, 43-53.

Person-Le Ruyet, J., Galland, R., Le Roux, A., Chartois, H., 1997. Chronic ammonia toxicity in juvenile turbot (Scphthalmus maximus). Aquaculture 154, 155-171.

Pinto, W., Aragão, C., Soares, F., Dinis, M.T., Conceição, L.E.C., 2007. Growth, stress response and free amino acid levels in Senegalese sole (Solea senegalensis Kaup 1858) chronically exposed to exogenous ammonia. Aquac. Res. 38, 1198-1204.
Rafatnezhad, S., Falahatkar, B., Tolouei Gilani, M.H., 2008. Effects of stocking density on haematological parameters, growth and fin erosion of great sturgeon (Huso huso) juveniles. Aquac. Res. 39, 1506-1513.

Reig, L., Duarte, S., Valero, J., Oca, J., 2010. Preference of cultured sole (Solea senegalensis) for different substrates differing in material, texture and colour. Aquac. Eng. 42, 82-89.

Rodiles, A., Herrera, M., Hachero, I., Rosano, M., Ferrer, J.R., Márquez, J.M., Navas, J.I., 2005. Influencia de distintos tipos de fondo en el preengorde del lenguado senegalés Solea senegalensis Kaup, 1958. Boletín Instituto Español de Oceanografía 21 (1-4), 177-181.

Rodríguez, J.L., Peleteiro, J.B., 2014. Cuadernos de Acuicultura: Cultivo del lenguado sengalés (Solea senegalensis). Fundación Observatorio Español de Acuicultura, Madrid.

Savage, D., Noy, D., Mihara, M., 2002. Modelling the interaction of bentonite with hyperalkaline fluids. Appl. Geochem. 17, 207-223.

Shi, X., Xie, N., Fortune, K., Gong, J., 2012. Durability of steel reinforced concrete in chloride environments: an overview. Constr. Build. Mater. 30, 125-138.

Siddique, R., 2011. Utilization of silica fume in concrete: review of hardened properties. Res. Conserv. Recycl. 55, 923-932.

Summerfelt, S., Bebak-Williams, J., Tsukuda, S., 2001. Controlled systems: water reuse and recirculation. In: Wedemeyer, G.A. (Ed.), Fish Hatchery Management, 2nd ed. American Fisheries Society, Bethesda, Maryland.

Superior Health Council, 2015. Human Exposure to Caustic And/or Corrosive Substances (acids and Bases). Publication of the superior health council No. 9108.

Tadayon, M.H., Shekarchi, M., Tadayon, M., 2016. Long-term field study of chloride ingress in concretes containing pozzolans exposed to severe marine tidal zone. Constr. Build. Mater. 123, 611-616.

Taylor-Hobson, 2011. Exploring Surface Texture, a Fundamental Guide to the Measurement of Surface Finish, 7th ed. Taylor Hobson Ltd.

Thurston, R.V., Philipps, G.R., Russo, R.C., 1981. Increased toxicity of ammonia to rainbow trout (S gairdneri) resulting from reduced concentration of dissolved oxygen. Can. J. Fish. Aquat. Sci. 38, 983-988.

Tomasso, J.R., 1994. Toxicity of nitrogenous wastes to aquaculture animals. Rev. Fish. Sci. 2, 291-314.

Toutanji, H.A., Bayasi, Z., 1999. Effect of curing procedures on properties of silica fume concrete. Cem. Concr. Res. 29, 497-501.

Trník, A., Scheinherrová, L., Medved, I., Černý, R., 2014. Differential scanning calorimetry of high-performance concrete with burnt clay shale addition. International Conference on Heat Transfer, Fluid Mechanics and Thermodynamics 